\title{
Analysis of the Accuracy of Determining the Coordinates Property Borders
}

\author{
Paweł Hanus, Elżbieta Jasińska, Edward Preweda \\ AGH University of Science and Technology, 30 Mickiewicza Av. pav. C-4, rooms303,415, 30-059 Krakow, Poland
}

\begin{abstract}
Property boundary points define the extent of property rightsin the field. For this reason, the precision of these coordinates is one of the most crucial factors which decide in both cases: the surface area of the property and the accuracy of this field and about the reliability limits and therefore the credibility of the cadastral system of the state. The ongoing process of cadastre modernization in Poland allows to improve the accuracy of the position of property boundary points. The coordinates of the boundary points can be fixed by various methods. Method of direct measuring in the field is preceded by the fixing of the boundaries in the presence of the owners. A photogrammetric method of marking out the boundaries basis of aerial photographs, the boundary points are or are not previously determined and indicated. The cartographic method for determining the coordinates of border points uses existing cadastral maps analogue, which has undergone a process of scanning and vectorization. The article presents an assessment of the accuracy of the coordinates designate the border points using the traditional method. It has been shown that the extent to which the accuracy of the coordinates is affected by the accuracy and establish the configuration points.
\end{abstract}

Keywords: border point; the accuracy of the points; real estate; cadastre.

\section{Introduction}

The basis for determination of land in property registers are data about land parcels recorded in the cadastre. The method of obtaining data about the boundaries of the property, including the accuracy of these data, over the years underwent many changes. Differences in the methods of obtaining, recording of accuracy or the ways of recording resulted, inter alia, from various legal and technical framework as a source of obtaining cadastral data. At the time of establishment in Poland, the current cadastre used boundaries and surfaces of both the cadastre documentation former Austrian partition, documentation former Prussian partition and from the processed and unprocessed aerial photographs. The accuracy of the data about many of these boundaries, however, leaves much to be desired and is often not appropriate, which should be determined by the location of border points.

Currently boundaries disclosed in the cadastre can be divided into the following types:

- boundaries established in the area in the presence of the owners, stabilized, measured and disclosed based on the surveying documentation approved by an administrative or judicial decision,

- boundaries disclosed, based on vectorization of a cadastral map calibrated raster or on the basis of the cadastral map digitization and disclosed in the process of modernization of the cadaster,

- boundaries obtained photogrammetric methods with advance fixing of their area and signaling.

The most important indicator that informs of the quality of the above-mentioned borders is the credibility (it can be identified with the attribute: data source - ZRD) and the accuracy of the position of the border (attribute: BPP). When these two factors usually strongly correlated to each other it allows to determine the accuracy of the surface area of the plot and the accuracy of the location of objects described in cadastre of investment, in regard to the limits.

It is worth mentioning that the crucialduring calculating the standard deviationofsurface area of the plot is the standard deviationof position of border points making up this plot, and the configuration of the plot. The maximum allowable difference in the plot calculated on the basis of measurements and surface disclosed in the cadastre defined the formula (1) [1]:

Corresponding author: Edward Preweda. E-mail address: preweda@agh.edu.pl

http://dx.doi.org/10.3846/enviro.2014.209

(C) 2014 The Authors. Published by VGTU Press. This is an open-access article distributed under the terms of the Creative Commons Attribution License, which permits unrestricted use, distribution, and reproduction in any medium, provided the original author and source are credited. 


$$
d P_{\text {max }}=m_{p} \sqrt{\frac{1}{8} \sum_{i=1}^{n} d_{i-1, i+1}^{2}}
$$

where:

$d P_{\max }$ - maximum (allowable) difference area of the plot calculated on the basis of geodetic measurements and area of the plot disclosed so far in the cadastre,

$m_{p} \quad-$ mean standard deviation of the position of the boundary point,

$d_{i-1, i+1}$ - the shortest diagonal located opposite to the point of issue of the i-th point.

This difference can be identified with the standard deviation of the surface area of the plot. Eqn (1) assumes equal standard deviations on both axes of the system. It is a special case, which is a considerable simplification of the problem.

At the end of this point, it is worth noting that under the amended Regulation in 2013 [2] coordinates of the of border points based on measurements of the situation and altitude should be characterized by standard deviation less than $0.30 \mathrm{~m}$ in relation to the 1 class network. This is importantdue to the factthat, as long as there is no changes of the regulation limit points should be determined with an accuracy of $0.10 \mathrm{~m}$ in relation to the geodetic control network, different classes ${ }^{\mathrm{a}}$ or measurements networks.

\section{Obtaining the coordinates of border points by direct measurement preceded by the determination borders in the field}

The most important element of direct measurement of the parcel borders is to previouslydetermine the location of these borders on the ground in the presence of interested parties. The fixed boundary points are the subject of situational measurement. At present, this measurement is carried out mainly by two methods:

- tachymeter method based on the surveying or measurement network

- GNSSmethodusingnetworkASG_EUPOSborTPI-NET

In case when border points are measured using tachymeter methods, their final standard deviation, compared to first class networks points, can be depended on standard deviation of:

- second and third class networks points,

- measurement network (when it was used/made),

- measurement (angles and distance).

According to Regulation of MAiC from 2012 [5] fundamental underlying network is a network of 1 class, the underlying network is a network base 2 class, and a detailed network is a network of 3 class. The standard deviation of horizontal 2-class network with respect to network 1 class should not exceed $0.01 \mathrm{~m}$. In turn, the horizontal accuracy of the third class a specific network, in relation to the establishment points (points of class 1 or 2) should not exceed [5]:

- $0,05 \mathrm{~m}$ in case of existing network second class,

- $0,10 \mathrm{~m}$ in case of existing network third class,

- $0,07 \mathrm{~m}$ in case of new points.

Where assumption measurement network is necessary to measure the boundary points, the network should have an average standard deviation of the position of the points not greater than $0.10 \mathrm{~m}$ of the nearest points of geodetic horizontal (1, 2 or 3 classes) [1]. For the standard deviation of $\mathrm{X}$ and $\mathrm{Y}$ coordinates that result from such established measurement networkwill consist of both dispersion establish points (geodetic network), network measurement inaccuracy and inaccuracy of measurement. On the other hand, taking into account the fact that the basic network fundamental class 1 form reference points the ASG-EUPOS, GNSS measurements using this network is a measure of equivalent reference directly to the 1st class.

\section{Assessment of accuracy designate the coordinates of border points by polar method}

One of the most commonly used classical methods of determining coordinates of the points is the polar method. This measurements are based on the network of reference points. It is worth notingthat in the caseof classicalgeodetic (surveing) networks, the coordinates of the reference pointsarecorrelatedwith each other, but that inpractice isignored. For individual classes geodetic network parameter for assessing the accuracy standard deviation of the position of the point is accepted, assuming at the same value $m_{x} i m_{y}$. For simple examples shown, as a way to establish affects the accuracy of the coordinates designate the boundary points.

a Poland has networks 1, 2 and 3 classes (surveying networks) and measurementone. The most precise is the 1 class network. According to the regulations applicable to 2012 surveying networks divided into Class I, II and III and the measurement network.

b Active Geodetic Network EUPOS - a nationwide network of reference stations, launched in 2008 and managed by the Head Office of Geodesy and Cartography, and which has continuous observation satellites GNSS

c TPI-NET - is a commercial network consisting of reference stations that reach throughout the Poland. The network supports the amendment surfaced as ASG-EUPOS. The main difference is access throughout the Polish land amendments GPS + GLONASS. 
Coordinates of point $\mathrm{P}_{i}$ (Fig. 1) are determined according to the known relation:

$$
\begin{aligned}
& x_{i}=X_{j}+d_{i} \cos \left(A_{j k}+\alpha_{i}\right) \\
& y_{i}=Y_{j}+d_{i} \sin \left(A_{j k}+\alpha_{i}\right)
\end{aligned}
$$

where:

$$
A_{j k}=\arctan \left(\frac{Y_{k}-Y_{i}}{X_{k}-X_{i}}\right)
$$

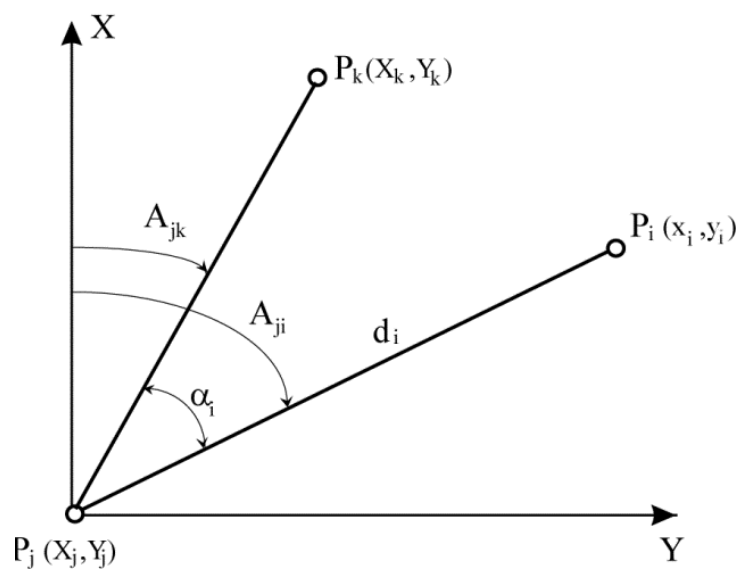

Fig. 1. Sketch illustrating the polar method

Using the right rise of variance matrix variance-covariance can be determined for the coordinates of the point $\mathrm{P}_{i}[3]$ :

$$
\operatorname{Cov}\left(x_{i}, y_{i}\right)=\mathbf{F}_{i}^{T} \operatorname{Cov}\left(X_{j}, Y_{j}, X_{k}, Y_{k}, d_{i}, \alpha_{i}\right) \mathbf{F}_{i}
$$

where $\mathbf{F}_{i}=\left[\begin{array}{l|l}\mathbf{F}_{x_{i}} & \mathbf{F}_{y_{i}}\end{array}\right]$

Wectors $\mathbf{F}_{x_{i}}, \mathbf{F}_{y_{i}}$ are the partial derivatives of the function (2) taking into account Eqn (3). Calculating the derivative, after performing transformations we obtain:

$$
\mathbf{F}_{x_{i}}=\left[\begin{array}{rr}
\frac{\partial x_{i}}{\partial X_{j}}= & 1-d_{i} \sin A_{j i} \frac{\sin A_{j k}}{d_{j k}} \\
\frac{\partial x_{i}}{\partial Y_{j}}= & d_{i} \sin A_{j i} \frac{\cos A_{j k}}{d_{j k}} \\
\frac{\partial x_{i}}{\partial X_{k}} & d_{i} \sin A_{j i} \frac{\sin A_{j k}}{d_{j k}} \\
\frac{\partial x_{i}}{\partial Y_{k}} & -d_{i} \sin A_{j i} \frac{\cos A_{j k}}{d_{j k}} \\
\frac{\partial x_{i}}{\partial d_{i}} & \cos A_{j i} \\
\frac{\partial x_{i}}{\partial \alpha_{i}} & -d_{i} \sin A_{j i}
\end{array}\right] \quad \mathbf{F}_{y_{i}}=\left[\begin{array}{rrr}
\frac{\partial y_{i}}{\partial X_{j}}= & d_{i} \cos A_{j i} \frac{\sin A_{j k}}{d_{j k}} \\
\frac{\partial y_{i}}{\partial Y_{j}}= & 1-d_{i} \cos A_{j i} \frac{\cos A_{j k}}{d_{j k}} \\
\frac{\partial y_{i}}{\partial X_{k}}= & -d_{i} \cos A_{j i} \frac{\sin A_{j k}}{d_{j k}} \\
\frac{\partial y_{i}}{\partial Y_{k}}= & d_{i} \cos A_{j i} \frac{\cos A_{j k}}{d_{j k}} \\
\frac{\partial y_{i}}{\partial d_{i}}= & \sin A_{j i} \\
\frac{\partial y_{i}}{\partial \alpha_{i}} & d_{i} \cos A_{j i}
\end{array}\right]
$$

Variance-covariance matrix $\operatorname{Cov}\left(X_{j}, Y_{j}, X_{k}, Y_{k}, d_{i}, \alpha_{i}\right)$ is presented below: 


$$
\left[\begin{array}{cccc:cc}
V\left(X_{j}\right) & \operatorname{cov}\left(X_{j}, Y_{j}\right) & \operatorname{cov}\left(X_{j}, X_{k}\right) & \operatorname{cov}\left(X_{j}, Y_{k}\right) & 0 & 0 \\
/-/ & V\left(Y_{j}\right) & \operatorname{cov}\left(Y_{j}, X_{k}\right) & \operatorname{cov}\left(Y_{j}, Y_{k}\right) & 0 & 0 \\
/-/ & 1-/ & V\left(X_{k}\right) & \operatorname{cov}\left(X_{k}, Y_{k}\right) & 0 & 0 \\
1-/ & /-/ & /-/ & V\left(Y_{k}\right) & 0 & 0 \\
\hdashline 0 & 0 & 0 & 0 & V\left(d_{i}\right) & 0 \\
0 & 0 & 0 & 0 & 0 & V\left(\alpha_{i}\right)
\end{array}\right]
$$

As it was mentioned, the covariance between the coordinates of the points most often assumed to be equal to zero. This is a significant simplification of the problem. However, the same values of variance have a significant impact on the covariance matrix for the designated points, depending on the azimuth $A_{j k}$ and angle $\alpha_{i}$.

Let assume the inaccuracy position points $P_{j}, P_{k} m_{p}= \pm 30 \mathrm{~cm}\left(m_{x}=m_{y}\right)$. Let accurate measurement of the length $d_{i}$ and the angle $\alpha_{i}$. Establish points are located as in Figure 2, the distance between these points and length $d_{i}$ are the same. Depending on the determined angle $\alpha_{i}$ values of the standard deviationof point position $P_{i}$ was presented.

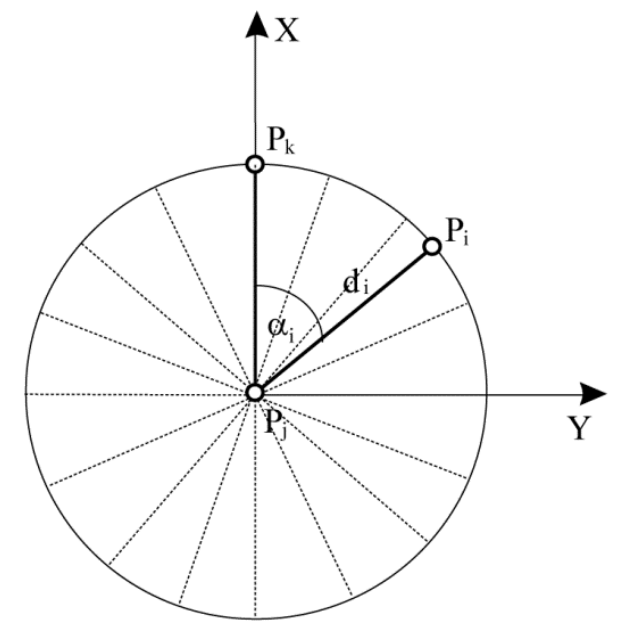

Fig. 2. Sketch of the position of the border point relative to the network

Table 1 presents the results of the calculations, which shows only affects the accuracy of references points for inaccuracy designated points. The table shows the value of the covariance between the coordinates $x_{i}$ and $y_{i}$. Covariance these should be taken into account while calculating the inaccuracy of the surface area of the plot [4]. Results in Table 1 are illustrated in Figure 3 .

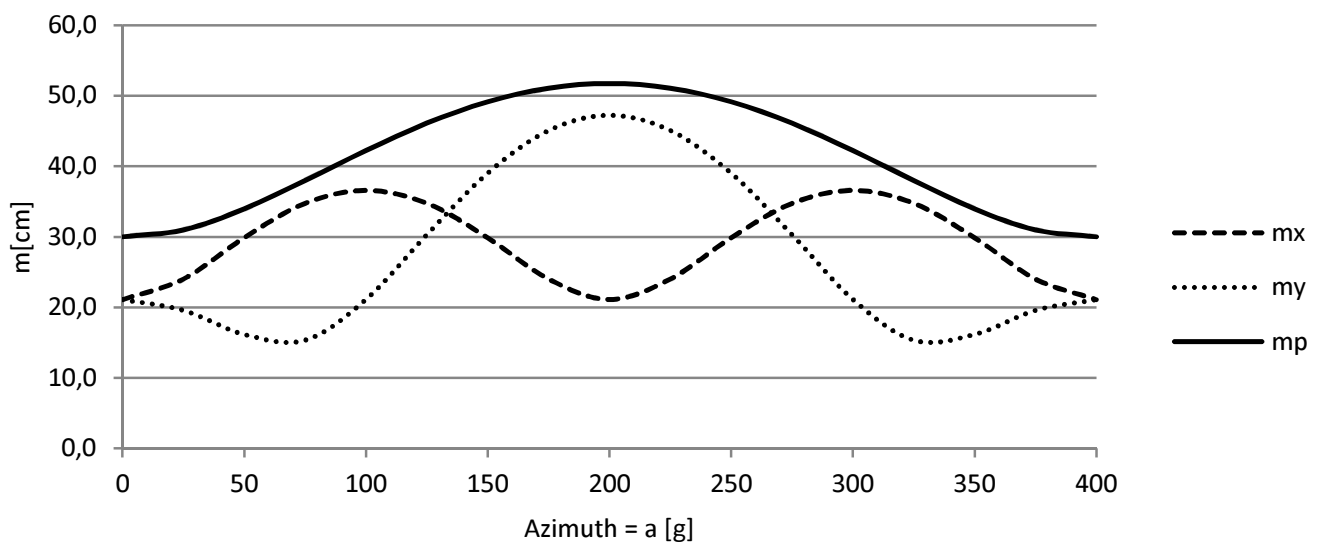

Fig. 3. Effect of the coordinates standard deviation depending on the angle $\alpha_{i}$ (azimuth) 
Table 1. Effect of accuracy to establish the standard deviation of the designated points

\begin{tabular}{llllc}
\hline$\alpha_{i}[g]$ & $m_{x}[\mathrm{~cm}]$ & $m_{y}[\mathrm{~cm}]$ & $m_{p}[\mathrm{~cm}]$ & $\operatorname{cov}\left(x_{i}, y_{i}\right)$ \\
\hline 0 & 21,1 & 21,1 & 30,0 & 0,0 \\
25 & 24,0 & 19,6 & 31,0 & $-144,7$ \\
50 & 29,9 & 16,2 & 34,0 & $-130,6$ \\
75 & 34,7 & 15,3 & 38,0 & 96,7 \\
100 & 36,6 & 21,1 & 42,2 & 446,1 \\
125 & 34,7 & 30,3 & 46,1 & 727,5 \\
150 & 29,9 & 39,0 & 49,1 & 761,5 \\
175 & 24,0 & 45,1 & 51,1 & 486,1 \\
200 & 21,1 & 47,2 & 51,7 & 0,0 \\
225 & 24,0 & 45,1 & 51,1 & $-486,1$ \\
250 & 29,9 & 39,0 & 49,1 & $-761,5$ \\
275 & 34,7 & 30,3 & 46,1 & $-727,5$ \\
300 & 36,6 & 21,1 & 42,2 & $-446,1$ \\
325 & 34,7 & 15,3 & 38,0 & $-96,7$ \\
350 & 29,9 & 16,2 & 34,0 & 130,6 \\
375 & 24,0 & 19,6 & 31,0 & 144,7 \\
400 & 21,1 & 21,1 & 30,0 & 0,0 \\
\hline
\end{tabular}

It should be noted that in the present case, the standard deviation values contained in the Table 1 and in Figure 3 are not dependent on the length $d_{i}$. In Table 2 and Figure 4 shows calculation results for the following values: $P_{j}(0,0), P_{k}(200,0)$, $m_{p}= \pm 30 \mathrm{~cm}\left(m_{x}=m_{y}\right)$.

Table 2. The impact of precision the references to the inaccuracy of the designated points, $d_{i}=200 \mathrm{~m} \pm 2 \mathrm{~cm}, \mathrm{~m}_{\alpha}= \pm 20 \mathrm{cc}$

\begin{tabular}{ccccc}
\hline$\alpha_{i}[g]$ & $m_{x}[\mathrm{~cm}]$ & $m_{y}[\mathrm{~cm}]$ & $m_{p}[\mathrm{~cm}]$ & $\operatorname{cov}\left(x_{i}, y_{i}\right)$ \\
\hline 0 & 29,1 & 22,1 & 36,6 & 0,0 \\
25 & 30,5 & 21,9 & 37,5 & $-17,2$ \\
50 & 33,4 & 22,0 & 40,0 & 49,6 \\
75 & 36,2 & 24,2 & 43,5 & 224,2 \\
100 & 37,3 & 29,1 & 47,3 & 446,1 \\
125 & 36,2 & 35,7 & 50,8 & 600,0 \\
150 & 33,4 & 41,9 & 53,6 & 581,2 \\
175 & 30,5 & 46,3 & 55,4 & 358,6 \\
200 & 29,1 & 47,8 & 56,0 & 0,0 \\
225 & 30,5 & 46,3 & 55,4 & $-358,6$ \\
250 & 33,4 & 41,9 & 53,6 & $-581,2$ \\
275 & 36,2 & 35,7 & 50,8 & $-600,0$ \\
300 & 37,3 & 29,1 & 47,3 & $-446,1$ \\
325 & 36,2 & 24,2 & 43,5 & $-224,2$ \\
350 & 33,4 & 22,0 & 40,0 & $-49,6$ \\
375 & 30,5 & 21,9 & 37,5 & 17,2 \\
400 & 29,1 & 22,1 & 36,6 & 0,0 \\
\hline
\end{tabular}




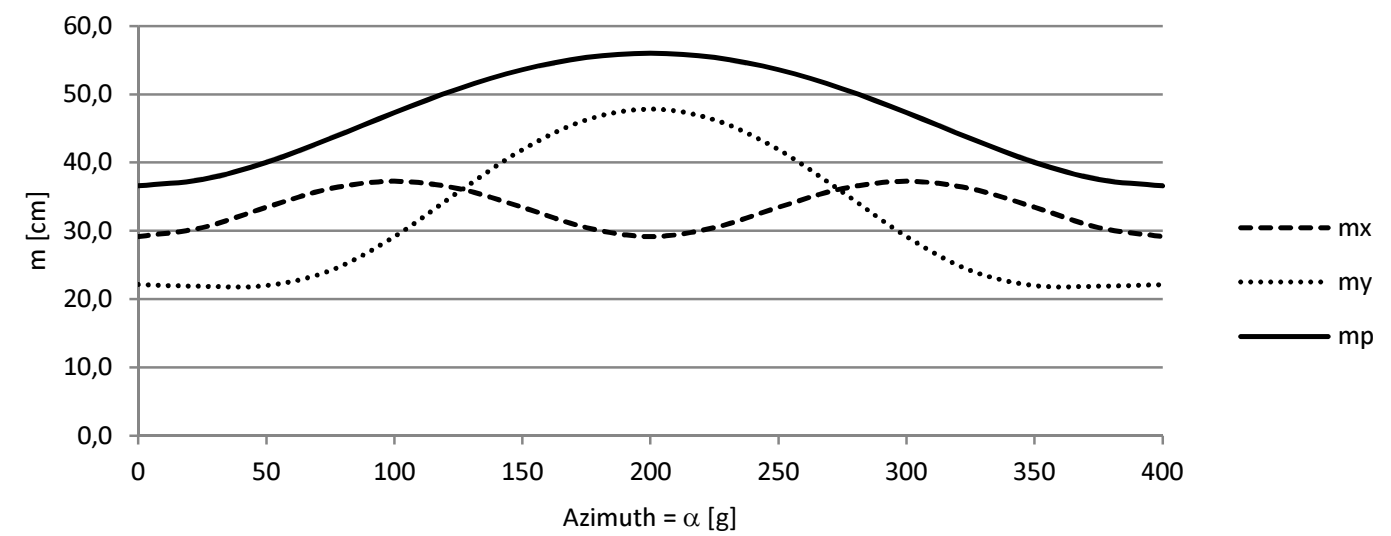

Fig. 4. The standard deviation of the position of the point depending on the angle $\alpha_{i}$ value

For comparison, Table 3 contains results for a length of $400 \mathrm{~m}$, the values of: $P_{j}(0,0), P_{k}(400,0), m_{p}= \pm 30 \mathrm{~cm}\left(m_{x}=m_{y}\right)$

Table 3. The impact of precision references points on the standard deviation of points designated, $d_{i}=400 \mathrm{~m} \pm 2 \mathrm{~cm}, m_{\alpha}= \pm 20 c c$

\begin{tabular}{llllr}
\hline$\alpha_{i}[\mathrm{~g}]$ & $m_{x}[\mathrm{~cm}]$ & $m_{y}[\mathrm{~cm}]$ & $m_{p}[\mathrm{~cm}]$ & $\operatorname{cov}\left(x_{i}, y_{i}\right)$ \\
\hline 0 & 29,1 & 24,6 & 38,2 & 0,0 \\
25 & 30,8 & 24,1 & 39,1 & $-59,1$ \\
50 & 34,3 & 23,3 & 41,5 & $-9,6$ \\
75 & 37,6 & 24,5 & 44,9 & 182,3 \\
100 & 38,8 & 29,1 & 48,5 & 446,1 \\
125 & 37,6 & 35,9 & 52,0 & 641,9 \\
150 & 34,3 & 42,6 & 54,7 & 640,4 \\
175 & 30,8 & 47,3 & 56,4 & 400,5 \\
200 & 29,1 & 49,0 & 57,0 & 0,0 \\
225 & 30,8 & 47,3 & 56,4 & $-400,5$ \\
250 & 34,3 & 42,6 & 54,7 & $-640,4$ \\
275 & 37,6 & 35,9 & 52,0 & $-641,9$ \\
300 & 38,8 & 29,1 & 48,5 & $-446,1$ \\
325 & 37,6 & 24,5 & 44,9 & $-182,3$ \\
350 & 34,3 & 23,3 & 41,5 & 9,6 \\
375 & 30,8 & 24,1 & 39,1 & 59,1 \\
400 & 29,1 & 24,6 & 38,2 & 0,0 \\
\hline
\end{tabular}

Analogous calculations were performed for many cases. Effects on maximum standard deviation of the position of the max $m_{p_{i}}$ only due to inaccuracies in the network $m_{p}$ (regardless of the length $d_{i}$ ), assuming that $m_{x}=m_{y}$ and the coordinate system as shown in Figure 1, shown in Table 4. A plot of the standard deviation of the maximum position of which is determined by precision the establishment points is shown in Figure 5, showing a linear relationship between the deviations.

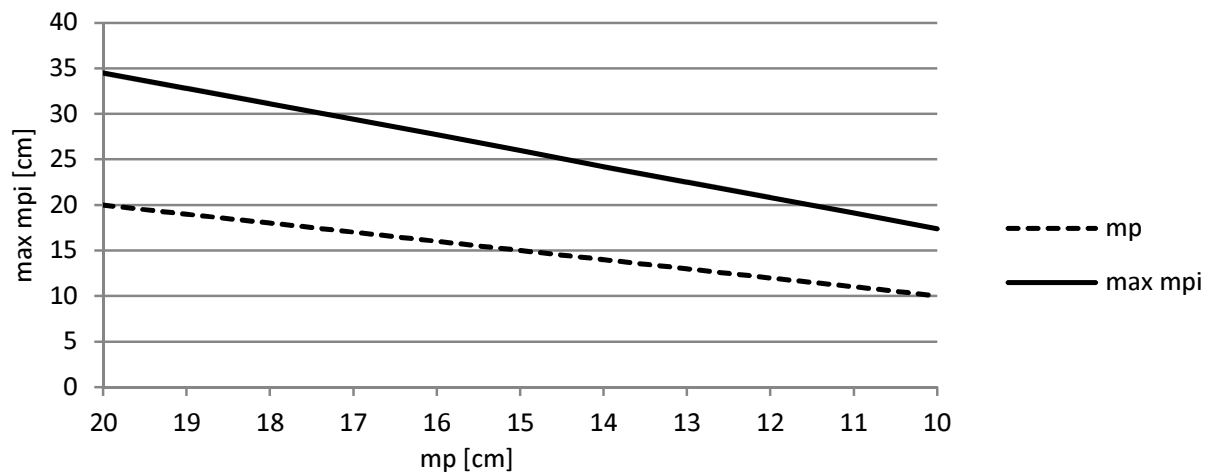

Fig. 5. Dependency graph maximum standard deviation of the position of determined point by the precision points to establish 
Table 4. The impact of precision references points on the standard deviation of the border point coordinates

\begin{tabular}{ll}
\hline$m_{p}[\mathrm{~cm}]\left(\right.$ dla $P_{j}$ oraz $\left.P_{k}\right)$ & $\max m_{p_{i}}[\mathrm{~cm}]$ \\
\hline 30 & 57,1 \\
20 & 34,5 \\
19 & 32,8 \\
18 & 31,1 \\
17 & 29,4 \\
16 & 27,7 \\
15 & 26,0 \\
14 & 24,2 \\
13 & 22,5 \\
12 & 20,8 \\
11 & 19,1 \\
10 & 17,4 \\
\hline
\end{tabular}

Taking into account standard deviations of the selected measuring the angle and length of the following values are obtained:

$$
\begin{aligned}
& \text { For } P_{j}(0,0), P_{k}(200,0), m_{p}= \pm 10 \mathrm{~cm}\left(m_{x}=m_{y}\right), d_{i}=200 \mathrm{~m} \pm 2 \mathrm{~cm}, m_{\alpha}= \pm 20 \mathrm{cc} \max m_{p_{i}}= \pm 27,2 \mathrm{~mm} . \\
& \text { For } P_{j}(0,0), P_{k}(400,0), m_{p}= \pm 10 \mathrm{~cm}\left(m_{x}=m_{y}\right), d_{i}=400 \mathrm{~m} \pm 2 \mathrm{~cm}, m_{\alpha}= \pm 20 \mathrm{cc} \max m_{p_{i}}= \pm 29,2 \mathrm{~mm} . \\
& \text { For } P_{j}(0,0), P_{k}(200,0), m_{p}= \pm 10 \mathrm{~cm}\left(m_{x}=m_{y}\right), d_{i}=200 \mathrm{~m} \pm 1 \mathrm{~cm}, m_{\alpha}= \pm 10 \mathrm{cc} \max m_{p_{i}}= \pm 20.3 \mathrm{~mm} . \\
& \text { For } P_{j}(0,0), P_{k}(400,0), m_{p}= \pm 10 \mathrm{~cm}\left(m_{x}=m_{y}\right), d_{i}=400 \mathrm{~m} \pm 1 \mathrm{~cm}, m_{\alpha}= \pm 10 \mathrm{cc} \max m_{p_{i}}= \pm 21,0 \mathrm{~mm} . \\
& \text { For } P_{j}(0,0), P_{k}(200,0), m_{p}= \pm 10 \mathrm{~cm}\left(m_{x}=m_{y}\right), d_{i}=200 \mathrm{~m} \pm 5 \mathrm{~mm}, m_{\alpha}= \pm 10 \mathrm{cc} \max m_{p_{i}}= \pm 18,4 \mathrm{~mm} . \\
& \text { For } P_{j}(0,0), P_{k}(400,0), m_{p}= \pm 10 \mathrm{~cm}\left(m_{x}=m_{y}\right), d_{i}=400 \mathrm{~m} \pm 5 \mathrm{~mm}, m_{\alpha}= \pm 10 \mathrm{cc} \max m_{p_{i}}= \pm 19,2 \mathrm{~mm} .
\end{aligned}
$$

\section{Construction of references}

The calculations indicate that the decisive factor in determining the precision coordinates of boundary points is accurate to references points. If the reference pointsareburdened withthe standarddeviation ofthe position order $18 \mathrm{~cm}$ orhigher, it means that only by this reason theinaccuracy ofthe pointdeterminedcan exceed $30 \mathrm{~cm}$. Assuming standard deviation of coordinates of the references points at level of $10 \mathrm{~cm}$ (points third class - according to the norms in force until 2012), the inaccuracy of determined points can be achieved at the level of $20 \mathrm{~cm}$. This value is in the range of $0.11-0.30 \mathrm{~m}$ appropriate to attribute $\mathrm{BPP}=2$. It is worth noting that in relation to such points until the entry into force of the amended regulation on the registration of land attribute BPP amounted 1. This is due to the fact that up to 31 December $2013^{\mathrm{d}}$ the position of boundary points referenced to geodetic control network, without distinction, whose class itwas.In practice, in most cases is the third classnetwork. It may be necessary to verify, even change in many cases, attributes of border points previously disclosed in the land register.

It should be alsonoted that the now tachymeters are commonly used, so the accuracy of the measurement of angles and lengths has minor importance. These issues will not be also taken place in the situation when border points of measurement GNSS methods, whether in reference to the ASG-EUPOS or TPI-NET network. In both cases, the results of these measurements are in fact related to the first class network.

\section{References}

[1] Rozporzqdzenie MSWiA z 9 listopada 2011 w sprawie standardów technicznych wykonywania geodezyjnych pomiarów sytuacyjnych i wysokościowych oraz opracowywania i przekazywania wyników tych pomiarów do państwowego zasobu geodezyjnego i kartograficznego (Dz. U. z 2011 r. Nr 263, poz. 1572)

[2] Rozporzqdzenie MRRiB z 29 marca 2001 r. w sprawie ewidencji gruntów i budynków (Dz.U. z 2001 r. Nr 38, poz. 454)

[3] Preweda, E. 2013. Rachunek wyrównawczy $\Rightarrow$ modele statystyczne [Adjustment computations $\Rightarrow$ statistical models]. Kraków, Wyd. PROGRES, 2013 r., ISBN: 978-83-938093-0-1

[4] Bieda, A.; Hanus, P.; Jasińska, E.; Preweda, E. 2014. Accuracy of determination of real estate area, in International Conference "Environmental Engineering", May 22-23, 2014, Vilnius, Lithuania

[5] Rozporzadzenie MAiC z dnia 14 lutego 2012 r. w sprawie osnów geodezyjnych, grawimetrycznych i magnetycznych (Dz U. z 2012 r. Poz. 352 )

\footnotetext{
${ }^{d}$ From 1 January 2014 in force is amended Regulation on the registration of land and buildings.
} 